\title{
Responses to Information Systems Graduate Preparation and Job Needs: Implications for Higher Education
}

\author{
DeShea Simon ${ }^{1, *} \&$ Kanata Jackson ${ }^{2}$ \\ ${ }^{1}$ Computer Science Department, Grantham University, 16025 West $113^{\text {th }}$ street Lanexa KS 66219, USA \\ ${ }^{2}$ School of Business, Hampton University, 100 E. Queen St. Hampton, Virginia 23668, USA \\ *Correspondence: Grantham University, Computer Science Department, 16025 West $113^{\text {th }}$ street Lanexa KS 66219 , \\ USA. Tel: 1-757-282-5732. E-mail: dsimon1@Grantham.edu
}

$\begin{array}{ll}\text { Received: January 20, } 2015 & \text { Accepted: April 3, } 2015 \quad \text { Online Published: October 11, } 2015 \\ \text { doi:10.5430/wje.v5n5p101 } & \text { URL: http://dx.doi.org/10.5430/wje.v5n5p101 }\end{array}$

\begin{abstract}
This study examined the perspectives on academic preparation and job skill needs of Information Systems program graduates from an Eastern state in the US. A historical review of the literature surrounding information systems skill requirements was conducted for this study, to provide an understanding of the changes in information systems over the past several decades. This historical look at the literature placed into perspective the fact that the field changes rapidly, causing the need for the information systems professional to also continuously change. The study employed a non-experimental, research design to allow a descriptive interpretation of the views of recent IS graduates. The results of the study revealed that a consensus exists regarding the perceptions of the skills needed for the information systems worker. However, graduates are concerned about how these skills are being delivered to develop competent information systems professionals for the work force.
\end{abstract}

Keywords: information systems; job needs; IS programs; job skills; job readiness

\section{Introduction}

The purpose of this research was to study the perspectives of academic preparation and job skill needs of IS program graduates. This examination can provide insight into the effectiveness of undergraduate programs and identify areas for collaboration and improvement in the development of information systems (IS) graduates for the work force. The evaluation of recent graduate opinions may lead to more effective identification of skill requirements and ways for industry to communicate necessary requirements to aid in the development of more skillful employees. A better understanding of these factors can assist in the formulation of recommendations to address the IS skills expectation gap.

The study findings will have importance for curriculum development and augmentation of university plans of study. Because academia is constantly trying to map, revise, update, and adjust skill development techniques, a deeper understanding of how to acquire current skills would help to improve the employee recruitment process. Information Systems solutions must be constructed and implemented rapidly and efficiently despite the constant changes in technology. Exploring ways to effectively understand skills needed in the discipline will help organizations to stay abreast of system analysis, design, and rapid application development that are vital to the success of IS deployment.

\section{Literature Review}

For the past 40 years, various articles have been written, from qualitative and quantitative perspectives, about the skill expectations needed by such technical professionals as IS workers and the satisfaction of the industry (Shrout ,1970; Cheney \& Lyons, 1980; Watson, Young,Miranda \& Seerly, 1990; Ashley \& Padget, 1998; Trauth, Farwell, \& Lee, 1995; Jacobson \& Armstrong, 200; Hardin, Joshi \& Li, 2002; Kittner and Papp, 2004; Kim, Hsu, \& Stern, 2006; Legier, Woodward \& martin, 2013). Understanding the skills needed of IS workers is imperative because as the economy changes, industry requirements also change, causing a need for skill requirements to be reassessed periodically. Therefore, a focus on the preparedness of IS graduates from the perspectives of graduates 
merits continuous research. Satisfying the staffing needs of the marketplace is a major focus for employers. IS hiring managers seek individuals who already possess practical experience and current IS skills. Since companies look to universities to provide such individuals, it is important to explore if individuals who intend to work in this discipline are adequately prepared by the academic institutions they attend.

\section{Methodology}

For this study, the researchers posed the following questions:

1. What Information Systems undergraduate program elements most helped and hindered success on the job for the Information Systems graduates?

2. In what ways did Information Systems undergraduate programs effectively meet instructional and job preparation needs of the Information Systems graduates?

3. What skills do the Information Systems graduates use on the job?

4. What Information Systems undergraduate program elements do Information Systems graduates lack that should be added to strengthen Information Systems undergraduate programs?

This type of information will allow stakeholders, such as IS hiring managers and IS professors, to explore more efficient tactics to strengthen the lines of communication of required skills needed by IS workers, thus resulting in more effectively prepared IS employees.

Twenty participants were randomly selected for this study. The participants came from three of the seven schools solicited for participation. Using the professional networking site LinkedIn, recent university graduates were identified as candidates for participation in the study. To identify participants using LinkedIn, the researchers followed the steps within the application to join seven university alumni groups in Eastern United States. Once access to the groups was available, recent IS graduates in the last 2 years were identified. Based on name and job title information obtained on LinkedIn, contact information for the individuals was retrieved via the World Wide Web open source information. Contact with potential participants was established through e-mail. The recruitment e-mail and the informed consent form were sent to each participant. The recruits were asked to fax or e-mail the signed informed consent form back to the researchers. All participants were asked to give consent over the telephone once more, prior to participating in the interview process.

This study used a non-experimental research design to allow a descriptive interpretation of the views of recent IS graduates. An interview guide was used to facilitate the collection of data from the participants. The document was divided into 4 distinct areas in order to collect information about program elements, job preparation, skill development and the state of information systems in university programs. Because of the exploratory nature of the study, no hypotheses were formulated or tested. However, a field test was performed to assess the appropriateness of the research questions. The test was performed with three terminally degreed individuals who were not participants in the study.

Semi structured telephone interviews were scheduled and held with each participant. The research was conducted using interview procedures that ensured the participants would not be identified directly or indirectly. All telephone interviews were digitally recorded while in progress and transcribed verbatim directly afterward. The transcripts were compared to the recordings to ensure validity, and the interview data were interpreted from a qualitative perspective. The researchers also collected and analyzed IS program curricula from the universities from which the participants graduated. The data was analyzed for patterns and themes that allowed the researchers to draw conclusions about the preparation of IS graduates.

\section{Results}

The first research question asked: "What information systems undergraduate program elements most helped and hindered success on the job for the information systems graduates?" The participants were asked to reflect on their core courses and answer a number of questions about the elements of their programs. The participants learned a number of skills. Table 1 shows the hard skills that participants stated they learned from their undergraduate IS program. Table 2 shows the soft (interpersonal) skills that participants stated they learned from their undergraduate IS program. Each of the tables also shows the frequency for each skill. Writing was the most mentioned hard skill. Writing process documents and providing systems reports appeared to be routine actions for the participants. Providing clear and accurate information is vital to the decisions and operations of an organization; therefore, IS 
workers must possess sufficient writing skills to provide information that allows managers and development teams to perform activities supporting organization goals.

Table 1. Hard Skills Learned in the Undergraduate Programs included in the Study

\begin{tabular}{ll}
\hline Hard skills learned & $n$ \\
\hline Writing & 8 \\
Business application use & 6 \\
Programming & 3 \\
Networking & 2 \\
\hline
\end{tabular}

Problem solving was the most mentioned soft skill. IS workers must possess the ability to work through issues to reach a resolution. These skills should be developed in a number of ways in order to prepare individuals to become flexible, critical thinkers. IS professionals may have to approach a problem mathematically or operationally; therefore, ability to think critically and provide viable solutions is extremely important in IS work. Although elements of system security can require hard skills when referring to integrating security hardware and software, one participant referred to system security from a soft skill perspective, stating that "deciding on policy and procedures for security measures is often a huge task."

Table 2. Soft Skills Learned in the Undergraduate Programs Included in the Study

\begin{tabular}{ll}
\hline Soft skills learned & $n$ \\
\hline Problem solving & 8 \\
Analysis & 5 \\
Teamwork & 3 \\
Management & 3 \\
Security Documentation & 1 \\
\hline
\end{tabular}

Based on the responses, more soft skills were expressed than hard skills. The majority of the participants said the materials used in the IS courses were timely. However, seven of the 20 participants expressed reservations about the outdatedness of course material. One participant summarized the responses concerning the instructional material, stating, "At the pace that technology moves, it's understandable that there will be a lapse in the materials presented in our courses. Therefore, the text and materials were not so far out of date that they were not applicable." Figure 1 shows a summary of the results.

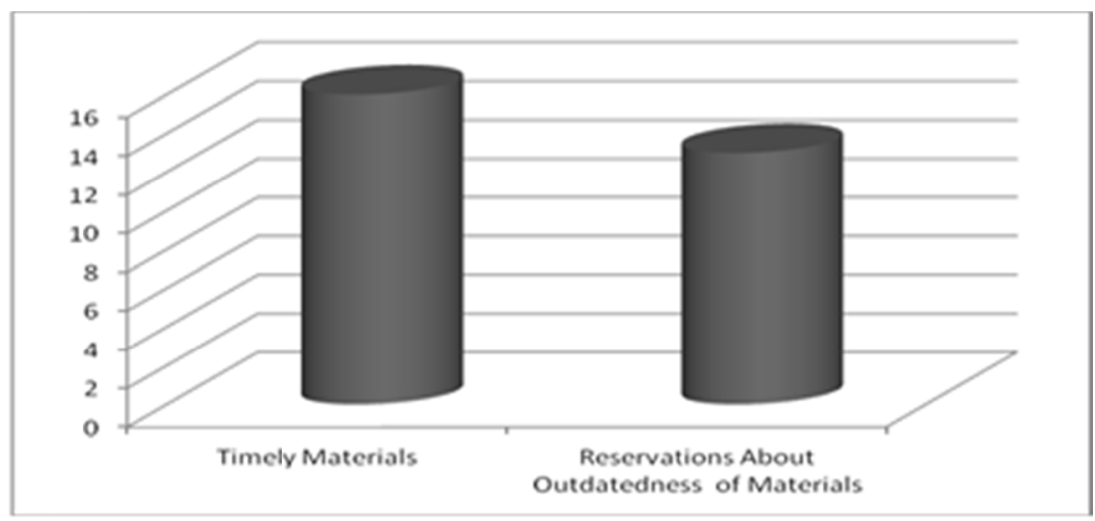

Figure 1. Perceptions on Timeliness of Course Materials

All of the participants were satisfied with the technologies used to deliver course material (see Figure 2). However, the researchers decided to probe for more information about course delivery and found that the delivery of the material is most often limited to lecture and PowerPoint presentations. One participant stated with conviction, "I would have loved more labs and chances to apply what I learned in the different lectures to get as much practice as possible." This suggests that a more active, hands-on approach to course delivery and learning is worth exploring. 


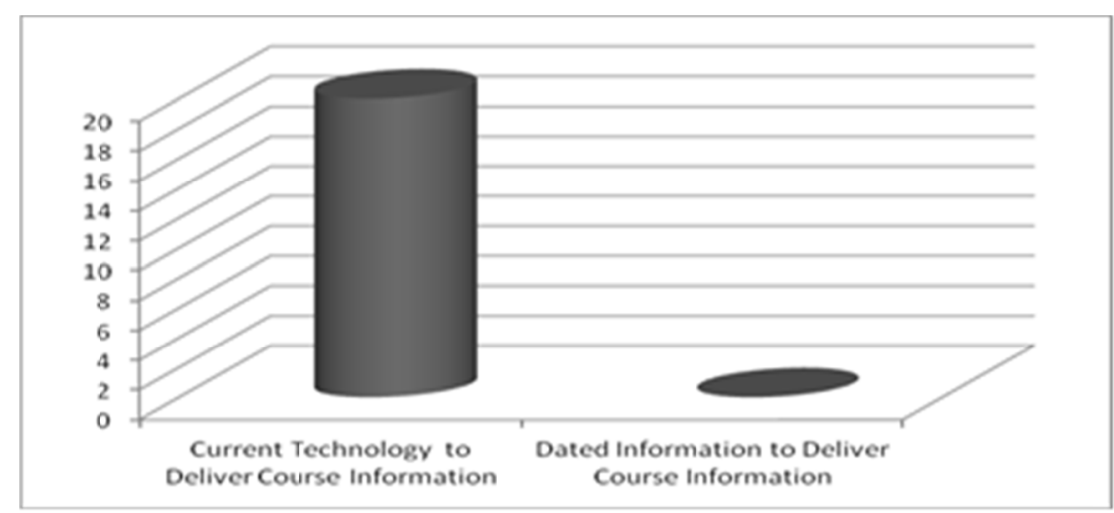

Figure 2. Perceptions on Technologies Used to Deliver Course Information

Various IS program elements were stated as necessary for the success of IS graduates. Based on the responses, a significant number of soft skills were provided by the respondents. One participant stated that a majority of my classes required me to work in teams, so I learned how to be a team player and I learned a lot from my classmates that I did not necessarily learn from the teacher or the textbook.

A second participant stated that strong communication, problem solving, research methods, and technical skills are useful for IS graduates. "Graduates will need these skills to help the organization where they work to stay competitive," stated the participant. A summary of the skills participants provided as useful for the success of IS graduates can be found in Figure 3.

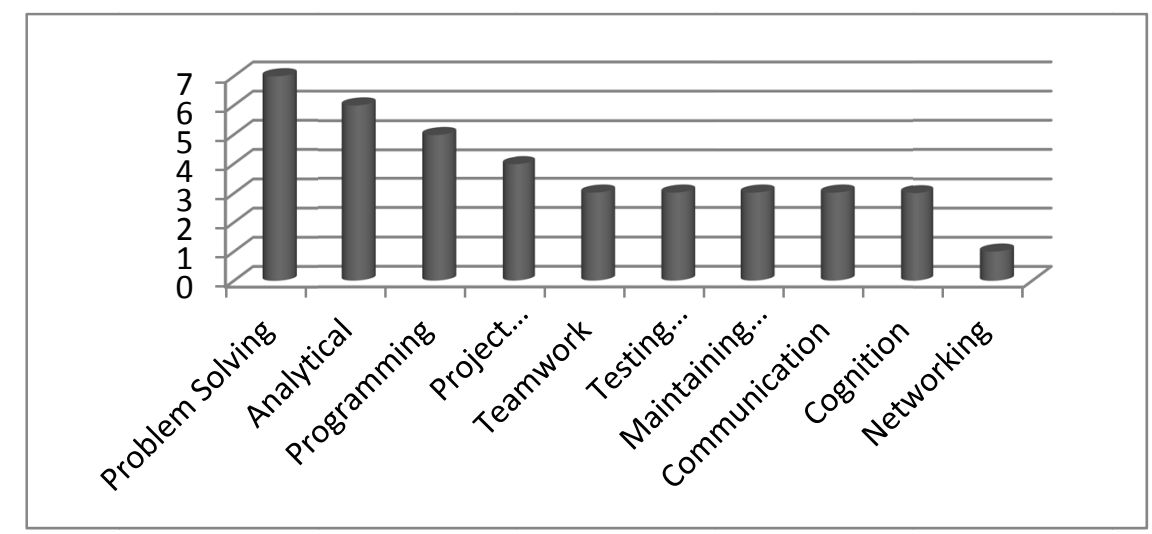

Figure 3. Skills Participants Provided as Useful for the Success of IS Graduates

When asked which elements were least useful, programming was the number one response. One respondent stated that "languages such as COBOL are out of date and I feel that I did not need to learn this language in my curriculum. I could have learned something else more useful." Another participant responded, "There were about five classes that focused heavily on programming in my program, while other platforms like iOS and database course materials suffered from lack of exposure."

Positive adjectives used to describe the experiences of the participants in their programs were "acceptable," "enjoyable," and "sufficient." One participant stated that the mix of materials in his program was "perfect for someone who was not trying to be a straight programmer or mathematician but still wanted to work in IT and have a cutting-edge skill set." "Stressful" was the only negative adjective given to describe experiences in an IS program. While participants found the lectures and course materials to be useful, the appeal for more hands-on activities relating to real-world business issues and situations surfaced continuously. However, participants stated that repetition, the expertise of the teachers, and practicing helped them to learn IS concepts.

Overall, the responses were positive about how well IS departments prepared participants for their current positions in IS (see Figure 4). One participant responded that the program provided significant preparation for the job market. 
Another stated, "My program helped me to develop skills that prepared me for my current position." A third participant said that her program was "as good as it could be without actual job training experience." A fourth participant stated that their IS development happened more on the job than in the program. However, what is interesting to note is that this student was willing to recommend the program to others. The rest of the participants were willing to recommend their programs as well.

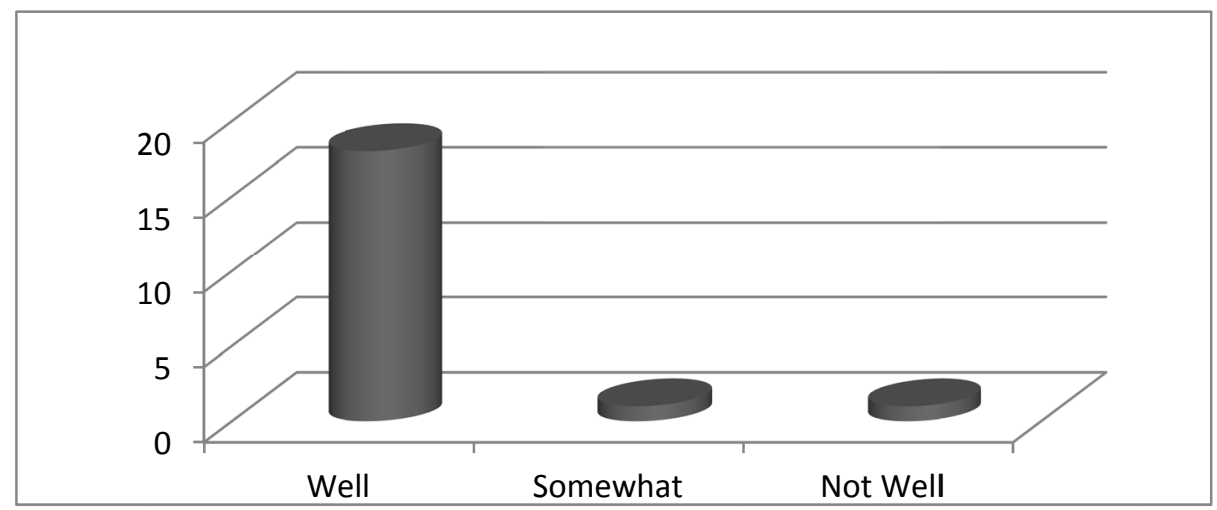

Figure 4. Perceptions on How Well Graduates Were Prepared for IS Work

The second research question asked, "In what ways did IS undergraduate programs effectively meet instructional and job preparation needs of the information systems graduates?" Ninety percent of the participants said the skills they acquired in their IS program are needed to do their job. A summary of the results are located in Figure 5. One participant stated, "Although I learned programming, I also learned analytical and communication skills, which helped me determine requirements and explain elements of coding to management in a manner that makes sense to them." This suggests that there is value in developing soft skills within university programs.

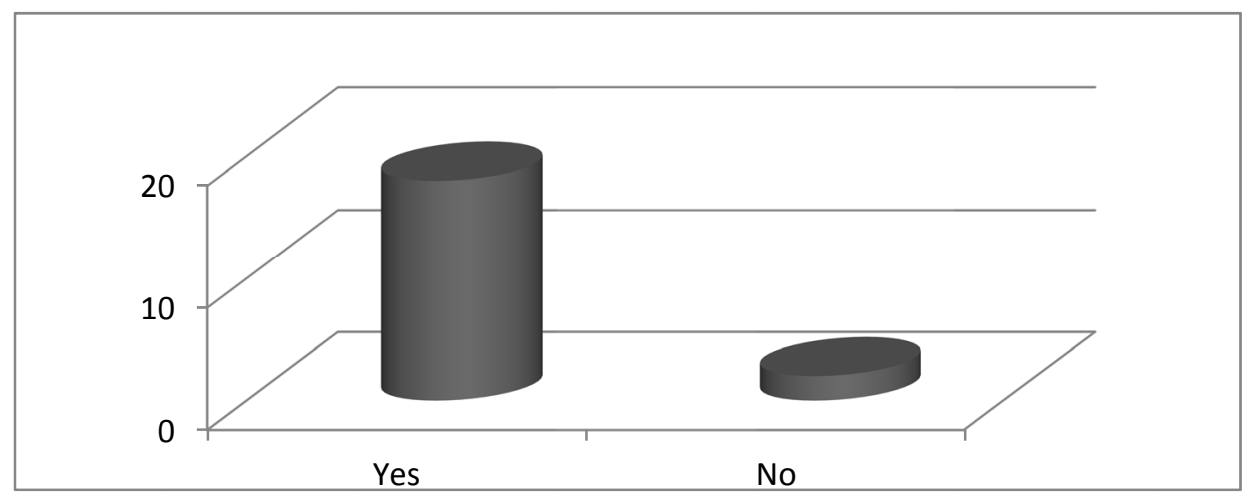

Figure 5. Responses on Whether Skills Acquired in IS Program Were Needed for IS Positions

The third research question asked, "What skills do information systems graduates use on the job?" Of the skills that were acquired, those that participants were using in their work are listed and categorized in Table 3. Five of the skills used on the job were hard skills and 7 of the skills were soft skills. 
Table 3. Skills Participants Use On the Job

\begin{tabular}{ll}
\hline \multicolumn{1}{c}{ Skills used } & \multicolumn{1}{c}{ Skill type } \\
\hline Testing applications & Hard skills \\
Networking & Hard skill \\
Security Implementation & Hard skill \\
Programming & Hard skills \\
Business application use & Hard skills \\
Writing & Hard skill \\
Teamwork & Soft skill \\
Problem solving & Soft skill \\
Verbal communication & Soft skill \\
Understanding Internet protocol & Soft skill \\
Analysis & Soft skills \\
Management & Soft skills \\
\hline
\end{tabular}

Based on participant responses, the course materials from the programs included in this study appear to have had a positive effect on the participants' maintaining their positions. One participant stated with excitement, "The courses have helped me tremendously! There were even times when we were covering something in class that I was actually doing at work for that week." A second participant described herself as "well rounded" because of the courses she took in her program. Figure 6 gives an overview of how well the course materials in the programs included in this study helped participants maintain their positions on the job.

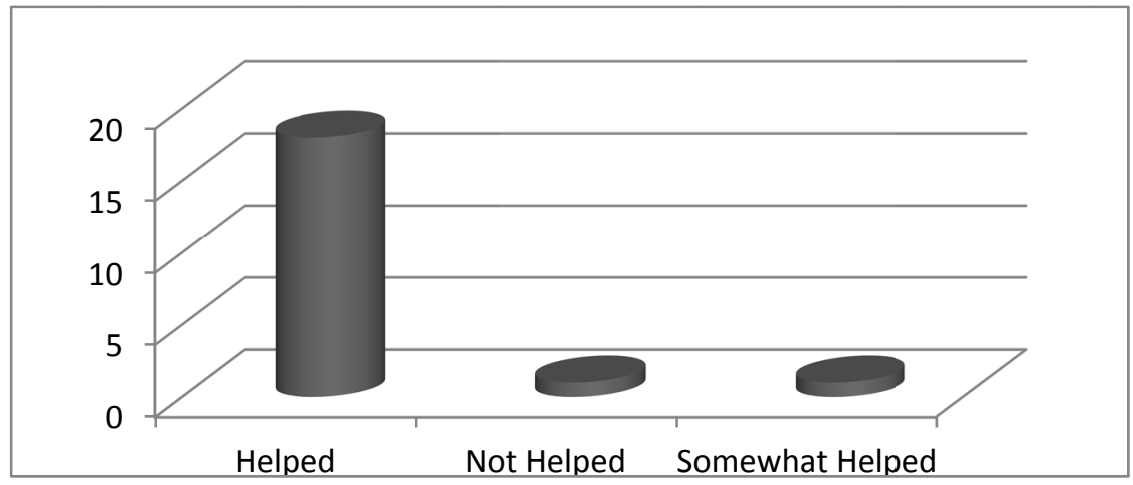

Figure 6. Perceptions of How Well Course Materials Help Graduates Maintain Their Jobs

The fourth research question asked, "What information systems undergraduate program elements do information systems graduates lack that should be added to strengthen information systems undergraduate programs?" The number-one additional area the participants needed on their job was SQL. SQL is an enterprise programming language designed for managing relational databases. According to "7 Key Skills" (2011), this is a key skill that graduates lack. Project management and gathering user requirements were also areas of concern. The researchers found that although participants may have been exposed to these subjects throughout their core courses, there was no formal instruction for these elements.

\section{Conclusion}

Although technology is moving at a rapid pace, the participants in this study stated the course materials were reasonably relevant. However, participants expressed some concern about the level of student engagement in the classroom as teaching methods were often limited to lectures and PowerPoint presentations. The majority of the participants said they were prepared for their jobs in information systems and they attributed their preparedness to the instruction received in their respective IS programs. All of the skills acquired by the participants were aligned with the skills mentioned in the literature as necessary for IS workers. With the exception of oral communication and an understanding of Internet protocol, the participants listed the same skills that they have learned as skills that they use on the job. This feedback suggests that the courses in the various programs have been used to effectively develop many of the essential skills needed to become competent IS professionals. 
The participants also shared that they experienced some anxiety about the number and types of programming languages taught. Half of the participants admitted that they thought twice about continuing in the IS track after realizing the number of programming classes that were required. Although programming is an appropriate element of IS curricula, there was concern about the number of course offerings and exposure to the programming courses best suited for IS work. Graduates recommended that SQL be the primary programming language for IS programs. This suggests that program leaders may need to reevaluate their curriculum requirements to ensure alignment of course offerings with skill development requirements of industry.

Programming languages such as Java, $\mathrm{C}$, and $\mathrm{C}++$ are among the most popular languages being used by computer scientists today. However, popular does not always mean functional or appropriate. SQL appears to be the most needed language in the IS discipline; therefore, IS majors should be competent in this language prior to graduation as they will become project managers, information systems analysts or database administrators, not computer scientists in most cases. Competency in SQL is necessary because it has become a part of most database architecture. The ability to run SQL statements in order to provide system updates, import new data into a database, or to extract information from the database are just some of the necessary activities IS workers must do to be effective on the job.

Graduates also recommended that programs include more simulations of performance requirements of the business environment. The requirements should be added to the core courses to better prepare graduates to address real-world problems with practical options that may be used for solutions. Such practice in the IS programs would better equip graduates entering the workplace. A majority of the participants said they read cases and were provided lectures on the problems but had very little in-class experience solving the problems individually or as teams.

Employment in the IS field is expected to grow through 2020 (Csory, 2013). This projection indicates that IS professionals will be in the forefront of organizations providing processes and procedures for implementation and integration of information technologies. The 21 st-century information systems professional must blend technical and interpersonal skills to effectively understand and communicate business operations and organization strategies. While academia is addressing most of the technical skills through course content, nontechnical skills appear to require development beyond the traditional classroom environment. This implies that institutions should examine their current programs to ensure that the skills current IS professionals are using are aligned with what is being developed through university programs. Figure 7 illustrates the skills that contribute to a prepared information systems graduate and the mediums that can be used to achieve the development of those skills for job preparation.

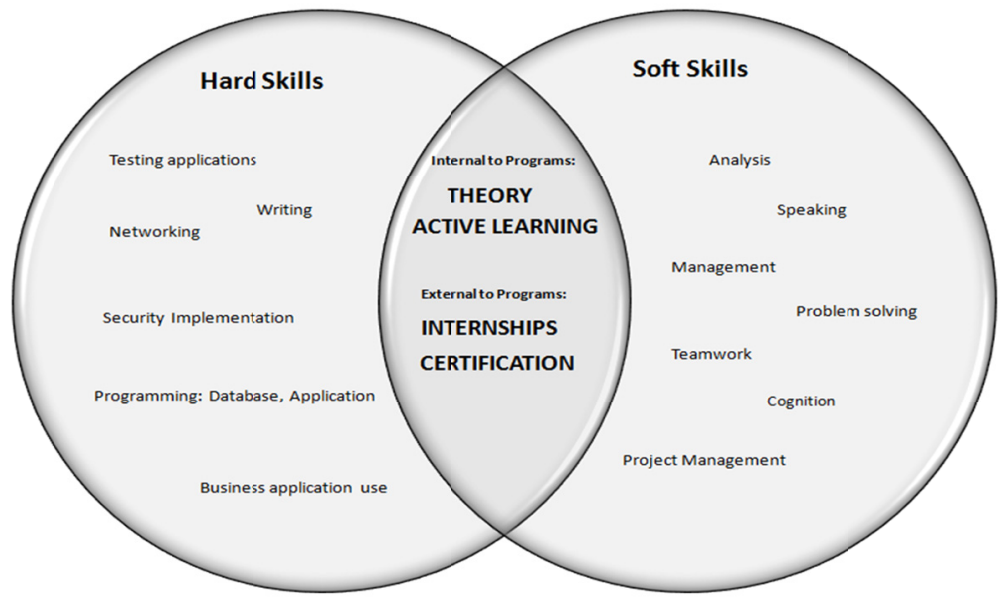

Figure 7. Skills Used in IS Work and Preparation Methods

Organizations look to universities to provide individuals prepared for the job market; therefore, it is important to explore if individuals who intend to work in this discipline are adequately prepared. A lack of required skills could lead to errors in data collection, hardware configuration, software development, and procedures. These inaccuracies cost a company time and money, impacting organizational growth and success. This study explored the required skills of IS graduates and if the graduates felt these skills were sufficient for IS positions in the job market. An improved understanding of the requirements needed for the job market between industry and academia can set the 
stage for continuous improvement of skill development.

\section{Future Research}

The researchers also identified opportunities for future research based on the skill requirement data provided by the participants. Several opportunities are evident based on the findings of the study. Upon review of the findings from this study, researchers could investigate the requirements for providing certifications to undergraduates, explore the perceptions of job preparation and IS skill requirements by gender, and even explore the impact of nontraditional classroom designs in the IS discipline.

\section{References}

7 key skills new IT grads are lacking. (2011). Computer World. Retrieved from http://www.computerworld.com/s/article/9220428/7_key_skills_new_IT_grads_are_lacking

Anderson, D. (2012). Can you do more with project management? Retrieved from http://technet.microsoft.com/en-us/gg634723.aspx

Ashley, N., \& Padget, T. (1998). Information systems graduates' evaluation of their curricula. Retrieved from http://www.westga.edu/ bquest/1998/infosys.html

Baugh, J., Davis, G., Kovacs, P., Scarpino, J., \&Wood, D. (2009). Employers and educators want information systems graduates to be able to communicate. Retrieved from www.iacis.org/iis/2009_iis/pdf/P2009_1209.pdf

Cashman, T., \& Rosenblatt, H. (2010). Systems analysis and design (9th ed.). Cambridge, MA: Course Technology.

Cheney, P. H., \& Lyons, N. (1980). Information systems skill requirements: A survey. MIS Quarterly, 4(1), 35-43. http://dx.doi.org/10.2307/248866

Creswell, J. (2003). Research design: Qualitative, quantitative, and mixed methods approaches (2nd ed.). Thousand Oaks, CA: Sage.

Drexel, P., \& Roberson, C. (2010). Using MBTI in a project-based systems analysis and design course. Retrieved from http://www.iiis.org/CDs2010/CD2010IMC/ICEME_2010/.../FB107FC.pdf

Figl, K. (2010). A systematic review of developing team competencies in information systems education. Journal of Information Systems Education, 21(3), 323-337.

Giangrande, E., Jr. (2009). Communication skills in the CS curriculum. Journal of Computing Sciences in Colleges, 24(4), 74-79.

Hardin, M., Joshi, K., \& Li, X. (2002). Business as usual? IS job skills requirements during the Internet era. Proceedings of the 8th Americas Conference on Information Systems, 2143-2150.

Horgan, R. (2012). History of LinkedIn. Retrieved from http://www.sophisticatededge.com/history-of-linkedin.html

Huang, H., Joshi, K. D., Kvasny, L., Mahar, J., \& Trauth, E. M. (2009). Synthesizing IT job skills identified in academic studies, practitioner publications and job ads. SIGMIS-CPR, 121-127. http://dx.doi.org/10.1145/1542130.1542154

Jackson, S. (2006). Program effectiveness of job readiness training: An analysis and evaluation of selected programs in St. Louis, Missouri. Doctoral dissertation, Capella University, Minneapolis, MN.

Keyes, R. (2006). The impact of Moore's law. Retrieved from www.ieee.org/portal/cms_docs_societies/sscs/.../200609.pdf

Kim, Y., Hsu, J., \& Stern, M. (2006). An update on the IS/IT skills gap. Journal of Information Systems Education, 17(4), 395-402.

Kittner, M., \& Papp, R. (2004, February). Tech skills in ten U.S. cities: Comparing job needs in a changing world. Paper presented at the Southern Association for Information Systems 7th annual conference, Savannah, GA.

Laudon, K. (2011). Occupation and career outlook for MIS majors 2012-2018. Retrieved from http://www.uncg.edu/bae/MIS_Outlook_2012-2018.pdf

Lieger, J., Woodward, B., \& Martin, N. (2012). Reassessing the skills required of graduates of an information systems program: An updated analysis. Proceedings of the Information Systems Educators Conference New Orleans, LA: Education Special Interest Group of the AITP, 1-11. 
McCubbrey, D., \& Scudder, R. (1988). The systems analysts of the 1990's. Proceedings of the ACM SIGCPR Management of Information Systems Personnel Conference, 8-16. http://dx.doi.org/10.1145/57216.57218

Outlay, C., \& Krishnan, P. (2010). Skill gaps and careers in IS compliance: Implications for IS degree programs in the U.S. Proceedings of the 2010 Special Interest Group on Management Information System's 48th annual conference on Computer Personnel Research (SIGMIS-CPR), 130-135. http://dx.doi.org/10.1145/1796900.1796953

Project Management Institute. (2013). A guide to the project management body of knowledge. Newtown Square, PA: Author.

Shelly, G. B., \& Rosenblatt, H. J. (2010). Systems analysis and design (8th ed.). Boston, MA: Course Technology.

Shrout, E. (1970). Competencies and training requirements for information systems analysts. Proceedings of the Ninth Annual Computer Research Conference, 75-100.

Stair, R., \& Reynolds, G. (2010). Fundamentals of information systems. Boston, MA: Course Technology.

Stevens-Huffman, L. (2011). Wanted: Problem-solving and communications skills. Retrieved from http://resources.dice.com/2011/12/16/problem-solving-hiring/

Surendra, N. C., \& Denton, J. W. (2009). Designing IS curricula for practical relevance: Applying baseball's money-ball theory. Journal of Information Systems Education, 20(1), 77-86.

Thibodeau, P. (2012). IT jobs will grow 22\% through 2020. Computer World. Retrieved from http://www.computerworld.com/article/2502348/it-management/it-jobs-will-grow-22--through-2020--says-u-s-. html

Topi, H., Valacich, J., Wright, R., Kaiser, K., Nunamaker, J., Sipior, J., \& Vreede, G. (2010). IS 2010: Curriculum guidelines for undergraduate degree programs in information systems. Communications of the Association for Information Systems, 1(26), 1-97.

Trauth, E., Farwell, D., \& Lee, D. (1993). The IS expectation gap: Industry expectations versus academic preparation. MIS Quarterly, 17(3), 293. http://dx.doi.org/10.2307/249773

Trauth, E., Lee, D., \& Farwell, D. (1995). Critical skills and knowledge requirements of IS professionals: A joint academic/industry investigation. MIS Quarterly, 3(19), 313-332.

U.S. Department of Labor, Bureau of Labor Statistics. (2010). Soft Skills to Pay the Bills - Mastering Soft Skills for Workplace Success. Retrieved from http://www.dol.gov/odep/topics/youth/softskills/

U.S. Department of Labor, Bureau of Labor Statistics. (2011). Occupational outlook handbook. Retrieved from http://stats.bls.gov/oco/home.htm

U.S. Department of Labor, Bureau of Labor Statistics. (2012). Soft skills: The competitive edge. Retrieved from http://www.dol.gov/odep/pubs/fact/softskills.htm

U.S. Department of Labor, Bureau of Labor Statistics. (2013). Careers in the growing field of information technology services. Retrieved from $\mathrm{http} / /$ www.bls.gov/opub/btn/volume-2/careers-in-growing-field-of-information-technology-services.htm

Watson, H., Young, D., Miranda, S., Robichaux, B., \& Seerly, R. (1990). Requisite skills for new. MIS Hires Data Base, 21(2), 20-29. http://dx.doi.org/10.1145/95367.95374

Wessels, D. (2007). The strategic role of project management. Retrieved from www .pmforum.org/library/papers/2007/PDFs/Wessels-2-07.pdf

Yin, K. (2013). Case study research: Design and methods (5th ed.). Thousand Oaks, CA: Sage. 